\title{
Feto-maternal outcomes following caesarean section: a prospective comparative study at tertiary care centre in North-Western Rajasthan
}

\author{
Neha Kuntal ${ }^{1}$, Madhu Patni Bhat ${ }^{1}$, Amit Nimawat ${ }^{2}$, \\ Munmun Yadav ${ }^{3 *}$, Mahendra Kumar Verma ${ }^{4}$
}

\begin{abstract}
${ }^{1}$ Department of Obstetrics and Gynecology, S.P. Medical College and P.B.M Hospital, Bikaner, ${ }^{2}$ Department of Paediatrics, NIMS Medical College Jaipur, Rajasthan, India

${ }^{3}$ Department of Obstetrics and Gynecology, SMS Medical College and Hospitals, Jaipur, Rajasthan, India

${ }^{4}$ Department of Preventive and Social Medicine, SMS Medical College and Hospitals, Jaipur, Rajasthan, India
\end{abstract}

Received: 26 March 2018

Accepted: 01 May 2018

\author{
*Correspondence: \\ Dr. Munmun Yadav \\ E-mail: dr.munmunyadav86@gmail.com
}

Copyright: (C) the author(s), publisher and licensee Medip Academy. This is an open-access article distributed under the terms of the Creative Commons Attribution Non-Commercial License, which permits unrestricted non-commercial use, distribution, and reproduction in any medium, provided the original work is properly cited.

\section{ABSTRACT}

Background: Caesarean section (CS) is employed when vaginal delivery is not feasible or hazardous to the mother and/or her baby. The procedure, however, is not without risk. We determined the fetomaternal outcomes of CS conducted at P.B.M Tertiary hospital situated in the North-Western region of Rajasthan.

Methods: This is a Hospital based prospective comparative study of all CSs performed for various indications at the Dept. of Gynaecology and Obst., S.P. Medical College and P.B.M Hospital, Bikaner, India, from August 01, 2016, to July 31, 2017. All patients who had CS at any time within the $24 \mathrm{~h}$ period were noted and followed up until discharge. The sociodemographic data, types of CS, indications, and feto-maternal outcomes were documented in a proforma. Statistical analysis was carried out using the SPSS version 24.

Results: There were 16386 deliveries out of which 4456 (27.1\%) were by LSCS. The age range of the group A was 21-25 years while in group B it was 26-30 years. The mean age group A was 22.4, and group B it was 27.9 years. Total 6572 primigravida patients delivered and $32.1 \%$ had LSCS. Total 9814 multigravida patients delivered and $12.6 \%$ had primary LSCS. In group A, 119(79.3\%) LSCS were elective as compared to group B where only $19(12.7 \%)$ were elective and this difference was found statistically highly significant ( $<<0.001)$. Indication of LSCS is different in both the groups. Fetal distress was most common indication in group A (53.3\%) while in group B most common indication was APH (35.9\%). Perinatal mortality/morbidity was significantly higher in group B (7.3\%) as compared to group A $(2.7 \%)$.

Conclusions: The CS rate in this study was $27.1 \%$. Although primary caesarean section in multipara constitutes only a small percentage of total deliveries and caesarean, they are associated with high maternal and perinatal morbidity. The reason for these complications is many. Beside obstetrical causes, factors like lack of antenatal care, low socioeconomic status, anaemia, malnutrition and illiteracy also play a major role obstructed labor and previous CS among Maternal and perinatal complications were more frequent with emergency CS and in the referred cases.

Keywords: Caesarean section, Fetomaternal-outcome, Parity

\section{INTRODUCTION}

Caesarean section represents the most significant operative intervention in obstetrics practice. This procedure has tremendously improved fetomaternal outcomes of pregnancy globally. ${ }^{1}$ The origin of CS is lost in antiquity and mythology. ${ }^{2}$ The indications and rates of CS delivery vary from country to country and from hospital to hospital though the overall incidence of CS shows a rising trend worldwide. The increasing, use of 
CS as a mode of delivery is due to improved safety of the procedure as a result of increasing use of antibiotics, blood availability, and improved aesthetic techniques. ${ }^{3} \mathrm{~A}$ sense of false security prevails in most of the multiparous women who had previous uneventful labour. As most of the multiparous women have had easy vaginal deliveries they do not pay much attention to the antenatal care they deserve. Moreover, the socio economic condition of these patients does not permit them to have adequate balanced diet, which the pregnant stage demands. These patients get expert supervision only when unforeseen emergency arises during pregnancy and labour. The relative ease with which some multiparous women deliver in the presence of faulty position and presentation may account for false sense of security. This invites laxity on part of patients as well as Obstetrician. Due to those factors the multiparous women pass through the stage of pregnancy and labour in a subnormal stage of health with a potential risk, when caesarean section has to be performed. ${ }^{4}$ In some countries, medical indications for CS have been replaced by mundane reasons such as social reasons, tocophobia, astrological (parents want the child to be born under favorable heavenly bodies constellations), and on maternal request. ${ }^{5,6}$

Despite the safety of CS, the procedure, especially in low - resource settings still poses challenges to the clinician. In the neonate, $\mathrm{CS}$ is associated with increased incidence of respiratory distress, high incidence of admission to the neonatal Intensive Care Unit, prolonged hospitalization, low Apgar scores at birth, iatrogenic prematurity, and transient tachypnea of the newborn. ${ }^{7}$

It is well-documented that CS carries a much higher maternal mortality and morbidity as compared to a vaginal delivery. ${ }^{8}$ In India, CS is becoming increasingly used as a mode of delivery and is a good practice to perform a periodic clinical audit of the fetal and maternal outcomes. The aim of our study is to maternal and fetal outcome following primary caesarean section in primigravida and multigravida and compare various indication and incidence for primary caesarean section in primigavida and multigravida at tertiary care hospital. It is envisaged that the information provided may lead to an improvement on this obstetric service.

\section{METHODS}

This is a hospital based prospective comparative study of all CSs performed for various indications at the Dept. of Gynaec and Obst., S.P. Medical College and P.B.M Hospital, Bikaner, India, from August 2016, to July 2017.

\section{Study setting}

The study was conducted at P.B.M Tertiary Hospital situated in the North-Western region of Rajasthan. It provides tertiary healthcare services to Bikaner states. It also acts as a major referral centre for high-risk obstetric cases from health institutions located within and outside the Bikaner. About 16000 deliveries take place annually in the hospital. The Obstetrics and Gynaecology Department has five labor suites, one each for the booked patients and referred cases. There is a functional obstetrics theatre, and a special care baby unit attached to the main labor room. The hospital runs residency programs in obstetrics and gynaecology, surgery, internal medicine, paediatrics, public health among other specialties. The institution is accredited for both the undergraduate and postgraduate medical training. Most of the clientele of the hospital belong to the middle- and low-income status.

\section{Study design}

Hospital based prospective comparative study carried out over a period of One years (August 2016, to July 2017). All patients who had CS at any time within the $24 \mathrm{~h}$ period were noted and followed up till discharge. Consent for the research was obtained verbally and in written forms. Women who had caesarean hysterectomy following uterine rupture were excluded from the study. Relevant information such as the sociodemographic variables, type of CS, indications, type of anaesthesia given, nature and types of anterior abdominal wall and uterine incisions, cadre of surgeon, postpartum blood loss, fetal and maternal outcomes were extracted from the case notes and operation files and documented in a proforma. The duty residents were informed about the study and were trained to fill the proforma. Parameters of fetal outcome were determined by Apgar scores at birth, neonatal intensive care admission, and perinatal mortality. The adverse maternal outcomewas determined by complications of surgery such as hemorrhage, surgical site wound infections (SSI), sepsis, and anemia among others.

\section{Data collection}

This includes the patients reporting directly to our hospital requiring elective or emergency caesarean section after trial, both primigravida and multigravida. All the patients taken up for study were to be followed up for 14 days. At the time of discharge, the patients were explained about the importance of spacing, contraception and immunization.

\section{Data analysis}

The data were entered and compiled in Microsoft excel which were further analyzed using SPSS version 24. Percentage and proportions were calculated. Chi-square test used for trend analysis as per data yield. The Hospital's Ethical and Research Committee approved the study.

\section{RESULTS}

During the study period, total 16386 patients delivered and out of them $4456(27.1 \%)$ delivered by LSCS. Total 
primary LSCS were 3344(20.4\%), total repeat LSCS were $1112(6.78 \%)$.

Table 1: Statistical.

\begin{tabular}{|lll|}
\hline Incidence & No. & $\%$ \\
\hline Total No. of deliveries & 16386 & 100 \\
\hline Total No. LSCS & 4456 & 27.1 \\
\hline Total number of primary LSCS & 3344 & 20.4 \\
\hline Total number of repeat LSCS & 1112 & 6.78 \\
\hline
\end{tabular}

Most common age group in group A was 21-25 years $(52 \%)$ while in group $\mathrm{B}$, most common age group was 26-30 years $(45.3 \%) .1 .3 \%$ cases were found between the age group of 31-35 years in group A and only $1(0.7 \%)$ case presented above the age of 35 years while in group B $15.3 \%$ cases were present between $31-35$ years of age and $4.7 \%$ cases were found after the age of 35 years and this difference was found statistically highly significant $(\mathrm{p}<0.001)$. Majority of patients came from rural area in both groups (56\% in group A and 62\% in group B).Most of patients in group A belongs to lower middle (36\%) and upper lower $(26 \%)$ class while in group B, most of patients belonged to upper lower $(51.3 \%)$ and lower $(30.7 \%)$ class.

Table 2: Socio-demographic profile of study participants.

\begin{tabular}{|lllll|}
\hline \multirow{2}{*}{ Age group (years) } & \multicolumn{3}{l}{ Group A } & \multicolumn{2}{l|}{ Group B } \\
\cline { 2 - 5 } & No. & $\%$ & No. & $\%$ \\
\hline $18-20$ & 48 & 32.0 & 4 & 2.7 \\
\hline $21-25$ & 78 & 52.0 & 48 & 32.0 \\
\hline $26-30$ & 21 & 14.0 & 68 & 45.3 \\
\hline $31-35$ & 2 & 1.3 & 23 & 15.3 \\
\hline$>35$ & 1 & 0.7 & 7 & 4.7 \\
\hline Total & 150 & 100 & 150 & 100 \\
\hline Residence & & & & \\
\hline Rural & 84 & 56.0 & 93 & 62.0 \\
\hline Urban & 66 & 44.0 & 57 & 38.0 \\
\hline Total & 150 & 100 & 150 & 100 \\
\hline Socioeconomic status & & & \\
\hline Upper & 11 & 7.3 & 0 & - \\
\hline Upper middle & 28 & 18.7 & 5 & 3.3 \\
\hline Lower middle & 54 & 36.0 & 22 & 14.7 \\
\hline Upper lower & 39 & 26.0 & 77 & 51.3 \\
\hline Lower & 18 & 12.0 & 46 & 30.7 \\
\hline Total & 150 & 100 & 150 & 100 \\
\hline
\end{tabular}

In group A, mild anemia seen in $67.3 \%$ of cases while moderate and severe anemia was seen in $28 \%$ and $4.7 \%$ of cases respectively. In group B, mild anemia was seen in $15.3 \%$ of cases, moderate anemia in $64 \%$ of cases while severe and very severe anemia was seen in $19.3 \%$ and $1.4 \%$ of cases respectively.
Table 3: Distribution of cases according to degree of anemia.

\begin{tabular}{|lllll|}
\hline \multirow{2}{*}{ Degree of anemia } & \multicolumn{2}{l}{ Gravida } & \multicolumn{2}{l|}{} \\
& \multicolumn{2}{l}{ Group A } & \multicolumn{2}{l|}{ Group B } \\
\cline { 2 - 5 } & No. & $\%$ & No. & $\%$ \\
\hline Mild $(10-11 \mathrm{gm} / \mathrm{dl})$ & 101 & 67.3 & 23 & 15.3 \\
\hline Moderate $(7-10 \mathrm{gm} / \mathrm{dl})$ & 42 & 28.0 & 96 & 64.0 \\
\hline Severe $(5-7 \mathrm{gm} / \mathrm{dl})$ & 7 & 4.7 & 29 & 19.3 \\
\hline $\begin{array}{l}\text { Very severe }(<5 \\
\text { gm/dl) }\end{array}$ & 0 & - & 2 & 1.4 \\
\hline Total & 150 & 100 & 150 & 100 \\
\hline Mean \pm SD & $8.92 \pm 1.42$ & $7.82 \pm 1.40$ \\
\hline P & $<0.001$ & \multicolumn{2}{l|}{} \\
\hline
\end{tabular}

Table 4: Distribution of cases according to emergency/elective LSCS.

\begin{tabular}{|lllll|}
\hline \multirow{2}{*}{ Elective/emergency } & \multicolumn{3}{l}{ Gravida } & \multicolumn{2}{l|}{ Group A } & \multicolumn{2}{l|}{ Group B } \\
\cline { 2 - 5 } & No. & $\%$ & No. & $\%$ \\
\hline Elective & 119 & 79.3 & 19 & 12.7 \\
\hline Emergency & 31 & 20.7 & 131 & 87.3 \\
\hline Total & 150 & 100 & 150 & 100 \\
\hline$\chi^{2}$ & 134.19 & & & \\
\hline $\mathrm{P}$ & $<0.001$ & & & \\
\hline
\end{tabular}

In group A, $119(79.3 \%)$ LSCS were elective as compared to group B where only 19(12.7\%) were elective and this difference was found statistically highly significant $(\mathrm{p}<0.001)$.

In group $\mathrm{A}$, most common emergency indication was fetal distress $(53.3 \%$ ) followed by primi breech with good size baby $(20.7 \%)$. In group B, although fetal distress was there in $30.2 \%$ cases but most common indication of LSCS was APH (35.9\%). Beside this other indication like mal-presentation, mal position, obstructed labour, impending rupture and cord prolapse were seen with higher incidence in group B as compared to group A (Table 5).

Overall postoperative complications rate were higher in multies in group A, complications were pyrexia $(6.3 \%)$, urinary infection $(4.2 \%)$, respiratory tract infection and wound infection was seen in $2.1 \%$ and $1.3 \%$ of cases respectively. In group $\mathrm{B}$, most common complication was pyrexia $(16 \%)$ followed by urinary infection $(7.3 \%)$. Beside this other complications like respiratory tract infection (6\%), wound infection and secondary suturing (4.7\% each), secondary PPH (3.3\%) and abdominal distension $(2.7 \%)$ is high in group B as compared to group A (Table 6).

Incidence of perinatal complications like early neonatal death were higher in group $\mathrm{B}(7.3 \%)$ as compared to group A (2.7\%). There was one still birth case in group A whereas 3 cases in group B (Table 7). 
Table 5: Distribution of cases according to Indication of LSCS.

\begin{tabular}{|c|c|c|c|c|c|c|}
\hline \multirow{3}{*}{ Indications } & \multicolumn{4}{|c|}{ Gravida } & \multirow{2}{*}{\multicolumn{2}{|c|}{ Total }} \\
\hline & \multicolumn{2}{|c|}{ Group A } & \multicolumn{2}{|c|}{ Group B } & & \\
\hline & No. & $\%$ & No. & $\%$ & No. & $\%$ \\
\hline Fetal distress & 72 & 53.3 & 42 & 30.2 & 114 & 41.6 \\
\hline Abruption & 5 & 3.7 & 17 & 12.2 & 22 & 8.0 \\
\hline Placenta previa with bout & 4 & 3.0 & 33 & 23.7 & 37 & 13.4 \\
\hline Impending rupture & 0 & - & 6 & 4.3 & 6 & 2.2 \\
\hline Obstructed labour & 2 & 1.5 & 9 & 6.5 & 11 & 4.0 \\
\hline Compound presentation & 0 & - & 4 & 2.8 & 4 & 1.5 \\
\hline Cord prolapse & 0 & - & 3 & 2.2 & 3 & 1.1 \\
\hline Transverse lie & 0 & - & 10 & 7.2 & 10 & 3.7 \\
\hline Brow presentation & 0 & - & 3 & 2.2 & 3 & 1.1 \\
\hline PROM with NPOL with breech & 7 & 5.2 & 3 & 2.2 & 10 & 3.7 \\
\hline PROM with NPOL & 17 & 9.6 & 9 & 6.5 & 26 & 9.5 \\
\hline Primi breech with good size baby & 28 & 20.7 & 0 & 0 & 28 & 10.2 \\
\hline Total & 135 & 100 & 139 & 100 & 274 & 100 \\
\hline
\end{tabular}

Table 6: Distribution of cases according to maternal postoperative complications.

\begin{tabular}{|c|c|c|c|c|c|c|}
\hline \multirow{3}{*}{ Postoperative complications } & \multicolumn{4}{|c|}{ Gravida } & \multirow{2}{*}{\multicolumn{2}{|c|}{ Total }} \\
\hline & \multicolumn{2}{|c|}{ Group A } & \multicolumn{2}{|c|}{ Group B } & & \\
\hline & No. & $\%$ & No. & $\%$ & No. & $\%$ \\
\hline Respiratory tract infection & 3 & 2.1 & 9 & 6.0 & 12 & 4.0 \\
\hline Abdominal distension & 0 & - & 4 & 2.7 & 4 & 1.3 \\
\hline Urinary infection & 4 & 4.2 & 11 & 7.3 & 15 & 5.0 \\
\hline Pyrexia & 6 & 6.3 & 24 & 16.0 & 30 & 10.0 \\
\hline Sub involution of uterus & 0 & - & 3 & 2.0 & 3 & 1.0 \\
\hline Wound infection & 2 & 1.3 & 7 & 4.7 & 9 & 3.0 \\
\hline Secondary PPH & 0 & - & 5 & 3.3 & 5 & 3.3 \\
\hline Secondary suturing & 0 & - & 7 & 4.7 & 7 & 2.3 \\
\hline
\end{tabular}

Table 7: Distribution of cases according to perinatal complications.

\begin{tabular}{|c|c|c|c|c|}
\hline \multirow{3}{*}{ Perinatal complications } & \multicolumn{4}{|c|}{ Gravida } \\
\hline & \multicolumn{2}{|c|}{ Group A } & \multicolumn{2}{|c|}{ Group B } \\
\hline & No. & $\%$ & No. & $\%$ \\
\hline No mortality & 145 & 96.7 & 134 & 89.3 \\
\hline Early neonatal death & 4 & 2.7 & 11 & 7.3 \\
\hline IUD & 0 & - & 2 & 1.4 \\
\hline Still birth & 1 & 0.6 & 3 & 2.0 \\
\hline Total & 150 & 100 & 150 & 100 \\
\hline
\end{tabular}

\section{DISCUSSION}

A sense of false security prevails in most of the pregnant women who had previous uneventful deliveries, they don't pay much attention to the antenatal care they deserve.

Moreover, the socioeconomic condition of the pregnant women, specially in our catchment area do not permit them to have adequate balanced diet and antenatal examination which the pregnant stage demands. Due to these factors, the lady is likely to pass through pregnancy in a sub normal stage of health and reach labour in a state of potential risk, and undetectable abnormality.

The hazards associated in such labours show that mother with previous history of eutocia and normal uneventful delivery, may exhibit dystocia and other abnormalities leading to impending bad foeto maternal outcome, and primary caesarean section in multies at times. The aim of 
our study is to compare various statistics in primary caesarean section in primi and multies.

This prospective study of comparing the primary caesarean section in primi gravida and multi gravida was conducted in the Department of Obstetrics \& Gynaecology, S.P. Medical College and A.G. of Hospitals, Bikaner which provided health care service predominantly to the rural population. Three hundred pregnant women selected for study and divided into 2 groups randomly i.e., Group A (primi gravida) and Group $\mathrm{B}$ (multigravida), contents of 150 cases each group.

Table 1 shows that total number of deliveries during study period of 1 year was 16386 and out of them $4456(27.1 \%)$ delivered by LSCS. Total number of primary LSCS $20.4 \%$ and repeat LSCS 1112(6.78\%). This statistical data not comparable with a study conducted by Desai et al where total percentage of caesarean section was $45.6 \%$, primary LSCS was $29.05 \%$ and repeat LSCS was $16.55 \% .^{9}$ This can be because in our catchment area, public reluctant for caesarean section because they believe that after a scar on body manual hard labour is difficult and once a caesarean section is always a caesarean section. Secondly our labour room doesn't have modern methods like continuous electronic fetal monitoring or scalp blood sampling for early detection of fetal distress so early fetal distress delivered vaginally.

In our study incidence of primary LSCS in primigravida was $32.1 \%$ and in multigravida $12.6 \%$. This incidence was comparable with study conducted by Rajput et al where incidence of primary caesarean section in primary gravida was $35.18 \%$ and $12.61 \%$ in multigravida. ${ }^{10}$

Table 2 shows most common age group in group A was 21-25 years $(52 \%)$ while in group $\mathrm{B}$, most common age group was $26-30$ years $(45.3 \%) .1 .3 \%$ cases were found between the age group of 31-35 years in group A and only $1(0.7 \%)$ case present above the age of 35 years while in group B $15.3 \%$ cases were present between 31 35 years of age and $4.7 \%$ cases were found after the age of 35 years and this difference was found statistically highly significant $(\mathrm{p}<0.001)$ which is comparable to study done by Suresh et al. ${ }^{4}$ Age distribution in both groups revealed an older age profile in multigravida. Majority of patient came from rural area in both groups $(56 \%$ in group A and $62 \%$ in group B). This shows geographical distribution of our tertiary care hospital these findings were comparable to study done by Saluja et al. ${ }^{11}$ Table 2 also shows that majority of patients belongs to lower socioeconomic class (62\% in group and $82 \%$ in group). This study is comparable with the study done by Rajput et al. ${ }^{10}$

Table 3 shows, in group A, mild anemia seen in $67.3 \%$ of cases while moderate and severe anemia was seen in $28 \%$ and $4.7 \%$ of cases respectively. In group B, mild anemia was seen in $15.3 \%$ of cases, moderate anemia was seen in $64 \%$ of cases while severe and very severe anemia was seen in $19.3 \%$ and $1.4 \%$ of cases respectively and this result comparable with the studies of Suresh et al and Rajput et al indicating the lack of nourishment and antenatal care in all pregnant women specially multiparous. ${ }^{4,10}$

Table 4 shows in group A $10 \%$ LSCS were elective as compared to group B where only $7.3 \%$ were elective. This again shows negligence of society towards multipara. These patients get expert supervision only when unforeseen emergency arises during pregnancy and labour. These results were comparable to study conducted by Suresh et al. ${ }^{4}$

Table 5 shows that in group A, most common emergency indication was fetal distress $(53.3 \%)$ followed by primi breech with good size baby $(20.7 \%)$. In group B, although fetal distress was there in $30.2 \%$ cases but most common indication of LSCS was APH (35.9\%). Beside this other indication like mal-presentation, mal position, obstructed labour, impending rupture and cord prolapse were seen with higher incidence in group B as compared to group A. Lack of antenatal care and intra-natal mismanagement by traditional birth attendant in multipara are responsible for these variations. Various studies, like Himanbindu et al, Rao et al, Desai et al shows similar results. ${ }^{12-14}$

Table 6 shows, overall postoperative complications rate were higher in multies. In group A, complications were pyrexia $(6.3 \%)$, urinary infection $(4.2 \%)$, respiratory tract infection and wound infection was seen in $2.1 \%$ and $1.3 \%$ of cases respectively. In group $\mathrm{B}$, most common complication was pyrexia (16\%) followed by urinary infection $(7.3 \%)$. Beside this other complications like respiratory tract infection $(6 \%)$, wound infection and secondary suturing (4.7\% each), secondary PPH (3.3\%) and abdominal distension $(2.7 \%)$ is high in group B as compared to group A. These results are comparable to study conducted by Rao et al. ${ }^{13}$ Table 7 reveals that incidence of perinatal complications like early neonatal death were higher in group B (7.3\%) as compared to group A $(2.7 \%)$. There was one still birth case in group A whereas 3 cases in group B. This result comparable to study conducted by Suresh et al and Himanbindu et al. ${ }^{4,12}$

\section{CONCLUSION}

Although primary caesarean section in multipara constitute only a small percentage of total deliveries and caesarean, they are associated with high maternal and perinatal morbidity.

The reason for these complications are many. Beside obstetrical causes, factors like lack of antenatal care, low socioeconomic status, anaemia, malnutrition and illiteracy also play a major role. 


\section{Recommendation}

Authors recommend that tertiary institutions should have an outreach enlightenment program for the community and traditional birth attendants in particular on the benefits of hospital supervised delivery and early referral of obstetric cases. Similarly, proper supervision of resident doctors during surgery is advocated.

\section{Funding: No funding sources}

Conflict of interest: None declared

Ethical approval: The study was approved by the Institutional Ethics Committee

\section{REFERENCES}

1. Nkwo OP, Onah HE. Feasibility of reducing caesarean section rate of the university of Nigeria teaching hospital, Enugu-Nigeria. TropJ Obstet Gynaecol. 2002;19:86-9.

2. Basket TF, Calder AA, Arulkumaran S, editors. In: Munro Kerr's Operative Obstetrics, Centenary ed. Edinburgh: Saunders Elsevier Ltd. (Pub); 2007: 151 166.

3. Ikechebelu JI, Mbamara SU, Afuba AN. Vaginal birth after one caesarean section: A review of the practice at Nnewi, Southeast Nigeria. J Med Med Sci. 2010;1:309-13

4. Suresh YA, Suresh YV. A prospective comparative study of caesarean section in multiparous and primiparous women. Int $\mathbf{J}$ Pharma Bio Sci. 2017;8(3):890-5.

5. Das A. Caesarean delivery on maternal request. Saudi J Health Sci. 2013;2:141-5.

6. Bhasin SK, Rajoura OP, Sharma AK, Metha M, Gupta N, Kumar S, et al. A high prevalence of caesarean section rate in East Delhi. Indian $\mathbf{J}$ Community Med. 2007;32:222-4.

7. Okeke TC, Onah N, Ikeako LC, Ezenyeaku CC, Nwogu-Ikojo C. Maternal and fetal outcome of elective caesarean section at 37-38 completed weeks of gestation in Enugu, Southeast Nigeria. Am J Clin Med Res. 2013;1:32-4.

8. Penna L. Management of the scarred uterus in subsequent pregnancies. Curr Obstet Gynaecol. 2003;13:173-8.

9. Desai E, Leuva H, Leuva B, Kanani M. A study of primary caesarean section in multi gravida. Int $\mathbf{J}$ Reprod Contracept Obstet Gynecol. 2013;2(3):320-4.

10. Rajput N, Singh P, Verma YS. Study of primary caesarean section in multigravida patients. Int $\mathrm{J}$ Reprod Contracept Obstet Gynecol. 2018;7(1):18591.

11. Saluja P, Roy K. Study of primary caesarean section in multiparous women. Natl J Integr Res Med. 2014;5(2):27-9.

12. Himabindu P, Tripura M. Primary Caesarean Section in Multipara. IOSR-JDMS. 2015;14(5):22-25.

13. Rao JH, Rampure N. Study of Primary Caesarean Section in Multiparous Women. J Evolu Med Dental Sci. 2013;2(24):4414-8.

14. Desai E, Leuva H, Leuva B, Kanani M. A study of primary caesarean section in multi gravida. Int $\mathbf{J}$ Reprod Contracept Obstet Gynecol. 2013;2(3):320-4.

Cite this article as: Kuntal N, Bhat M, Nimawat A, Yadav M, Verma MK. Feto-maternal outcomes following caesarean section: a prospective comparative study at tertiary care centre in NorthWestern Rajasthan. Int J Reprod Contracept Obstet Gynecol 2018;7:2311-6. 